Electronic Supplementary Information (ESI)

\title{
Ring-opening Copolymerizaton of Cyclohexene Oxide and Succinic Anhydride by Zinc and Magnesium Schiff-Base Complexes Containing Alkoxy Side Arms
}

\begin{abstract}
Arnut Virachotikul, ${ }^{a}$ Nattiya Laiwattanapaisarn, ${ }^{a}$ Phonpimon Wongmahasirikun, ${ }^{a}$
Parichat Piromjitpong, ${ }^{a}$ Kittipong Chainok, ${ }^{b}$ and Khamphee Phomphrai ${ }^{* a, c}$
\end{abstract}

${ }^{a}$ Department of Materials Science and Engineering, School of Molecular Science and Engineering, Vidyasirimedhi Institute of Science and Technology (VISTEC), Wangchan, Rayong 21210, Thailand. Email: khamphee.p@vistec.ac.th

${ }^{b}$ Materials and Textile Technology, Faculty of Science and Technology,

Thammasat University, Khlong Luang, Pathum Thani 12121 Thailand.

${ }^{c}$ Research Network of NANOTEC-VISTEC on Nanotechnology for Energy,

Vidyasirimedhi Institute of Science and Technology, Wangchan, Rayong 21210 Thailand. 


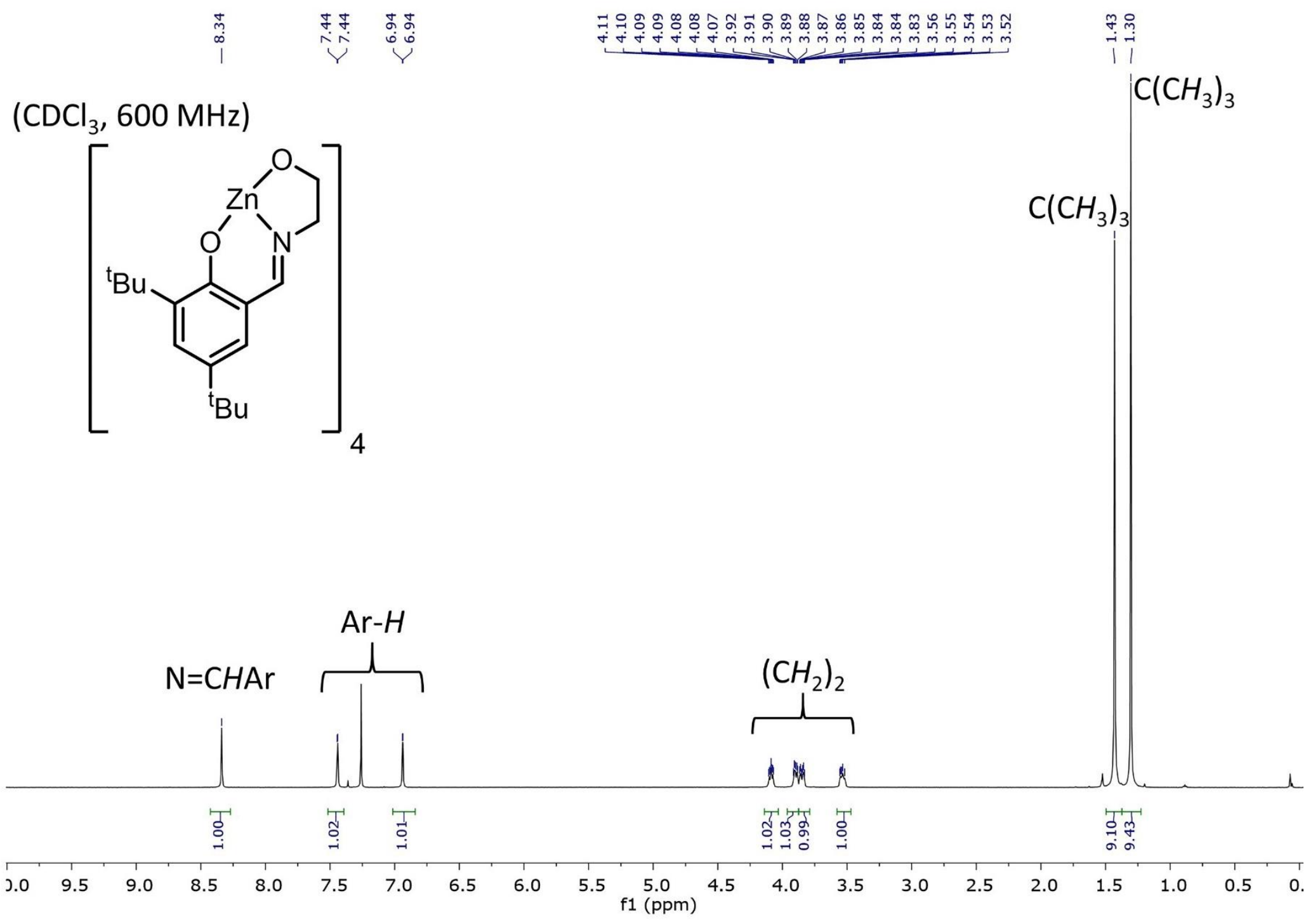

Figure $\mathbf{S 1}{ }^{1} \mathrm{H}$ NMR spectrum $\left(\mathrm{CDCl}_{3}, 600 \mathrm{MHz}, 30{ }^{\circ} \mathrm{C}\right)$ of complex $2 \mathbf{a}$. 

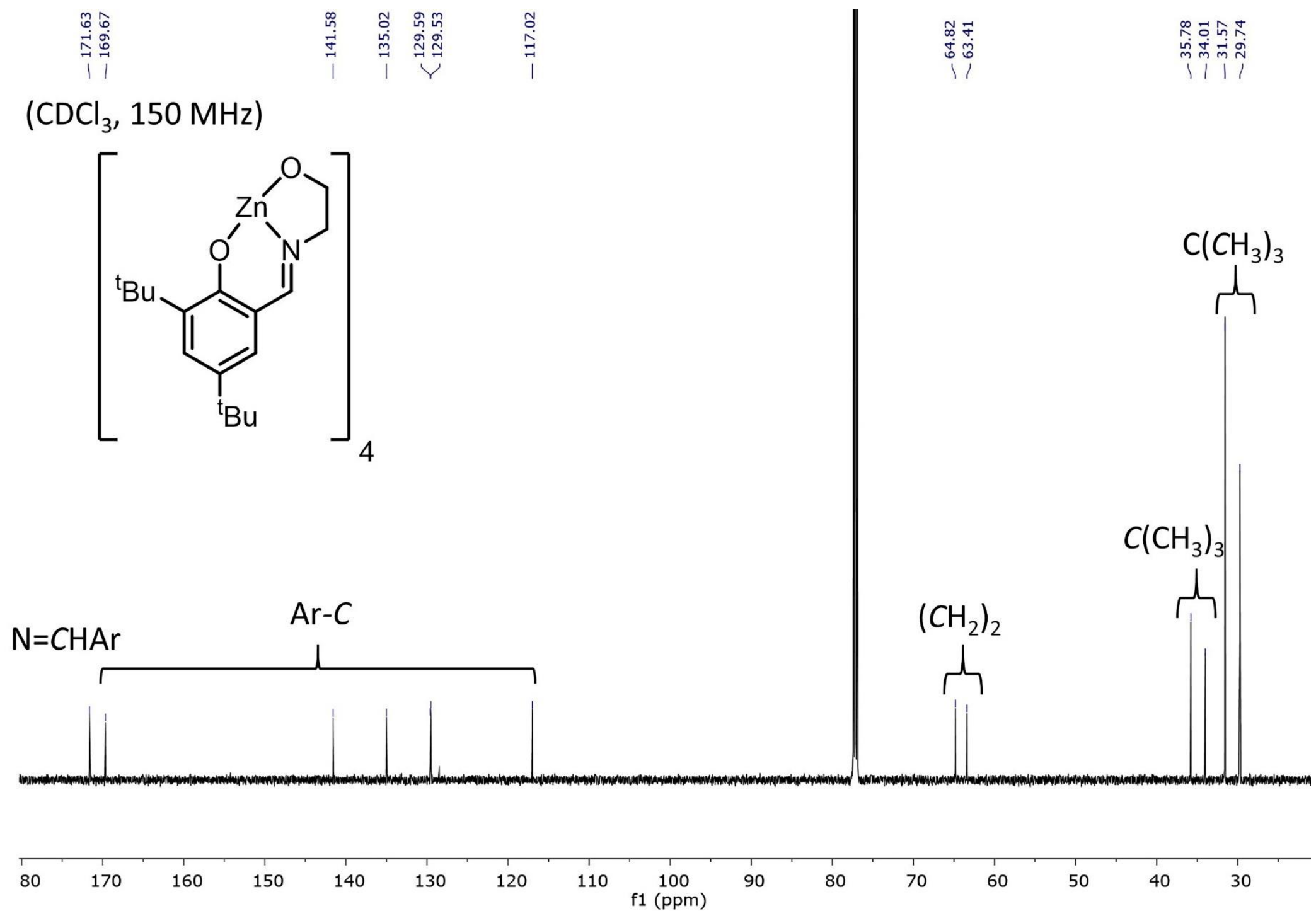

Figure S2 ${ }^{13} \mathrm{C}$ NMR spectrum $\left(\mathrm{CDCl}_{3}, 150 \mathrm{MHz}, 30{ }^{\circ} \mathrm{C}\right)$ of complex $2 \mathbf{a}$. 


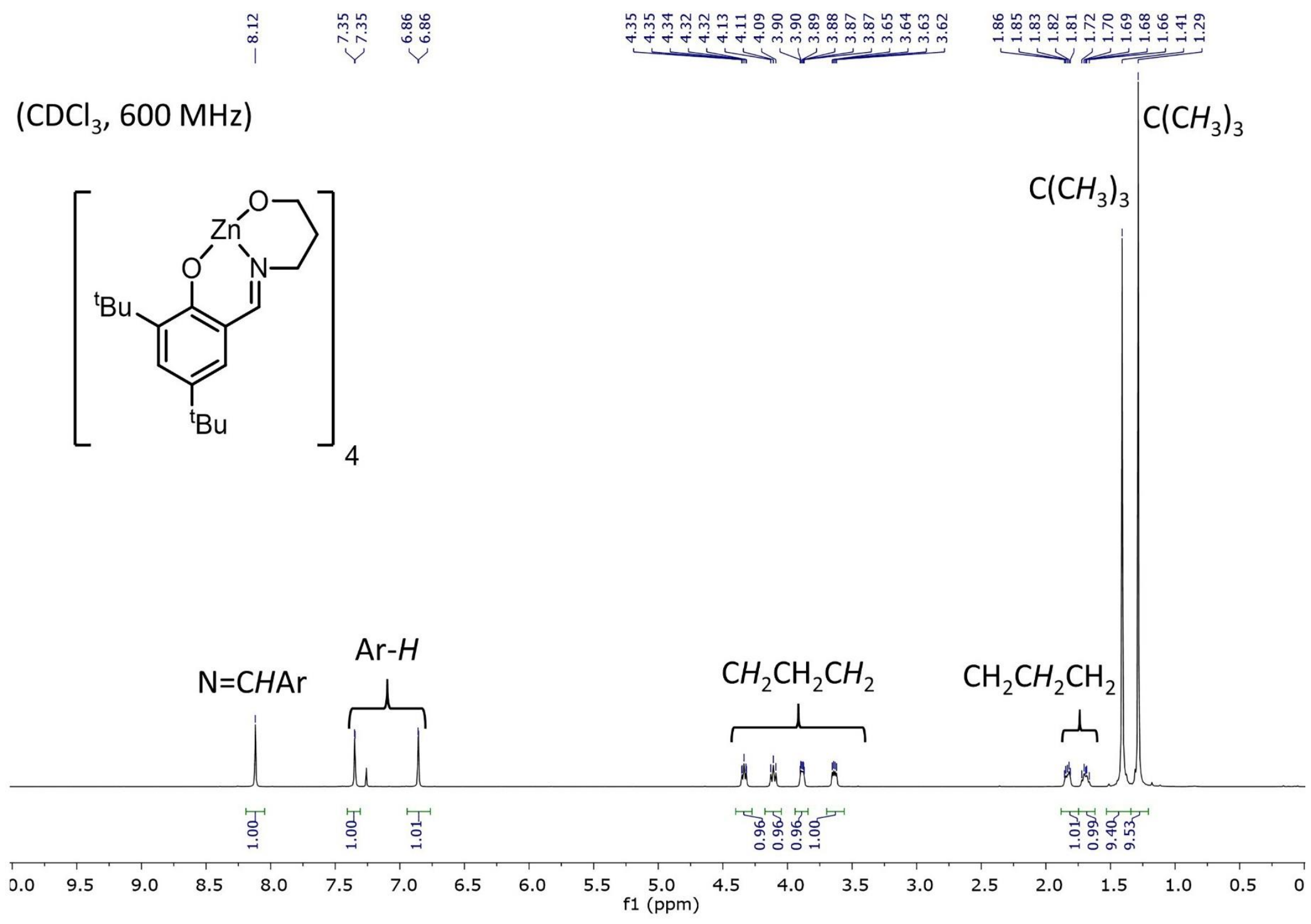

Figure $\mathbf{S 3}{ }^{1} \mathrm{H}$ NMR spectrum $\left(\mathrm{CDCl}_{3}, 600 \mathrm{MHz}, 30{ }^{\circ} \mathrm{C}\right)$ of complex $\mathbf{2 b}$. 

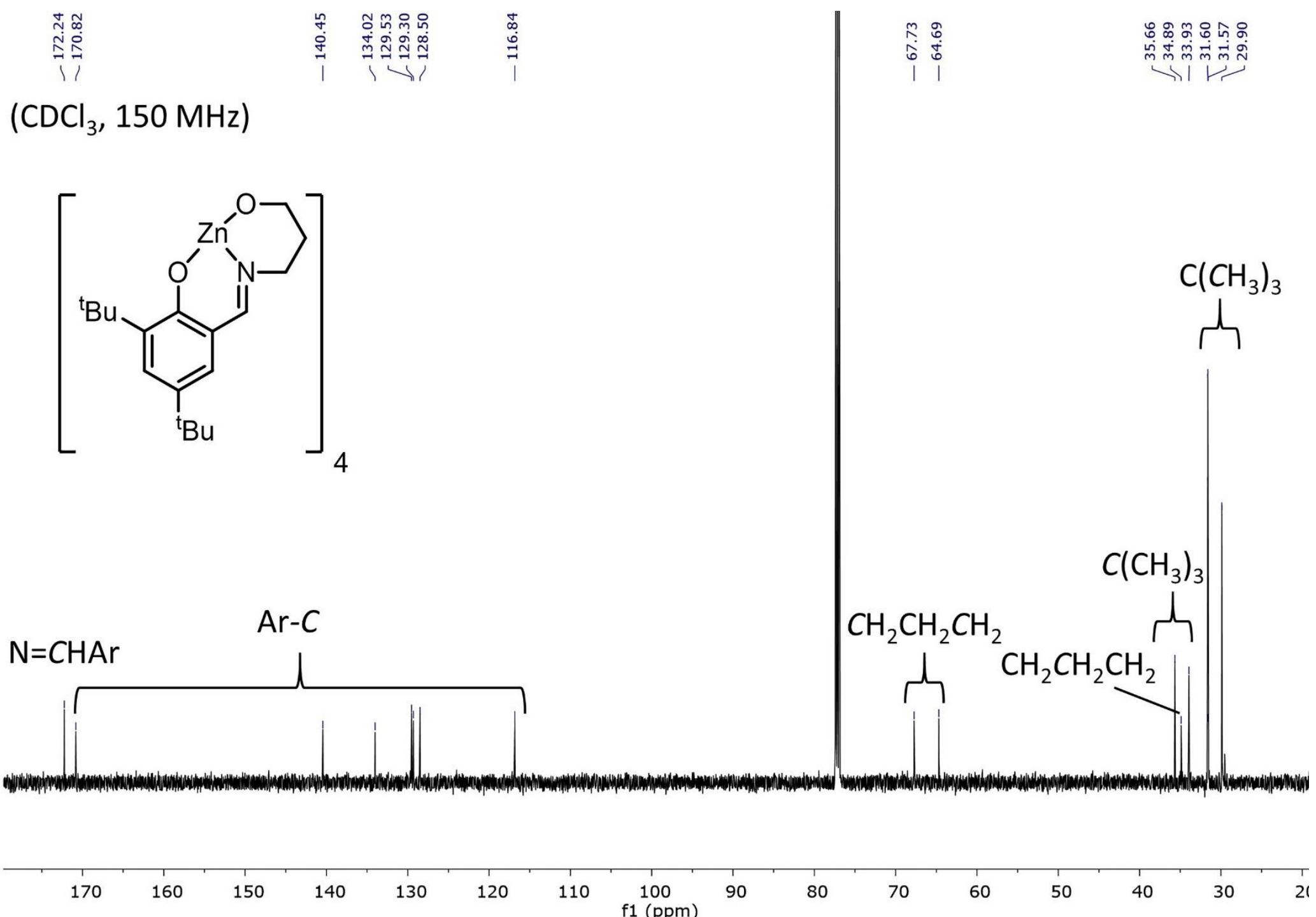

Figure $\mathbf{S 4}{ }^{13} \mathrm{C}$ NMR spectrum $\left(\mathrm{CDCl}_{3}, 150 \mathrm{MHz}, 30^{\circ} \mathrm{C}\right)$ of complex $\mathbf{2 b}$. 


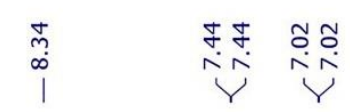

$\left(\mathrm{CDCl}_{3}, 600 \mathrm{MHz}\right)$
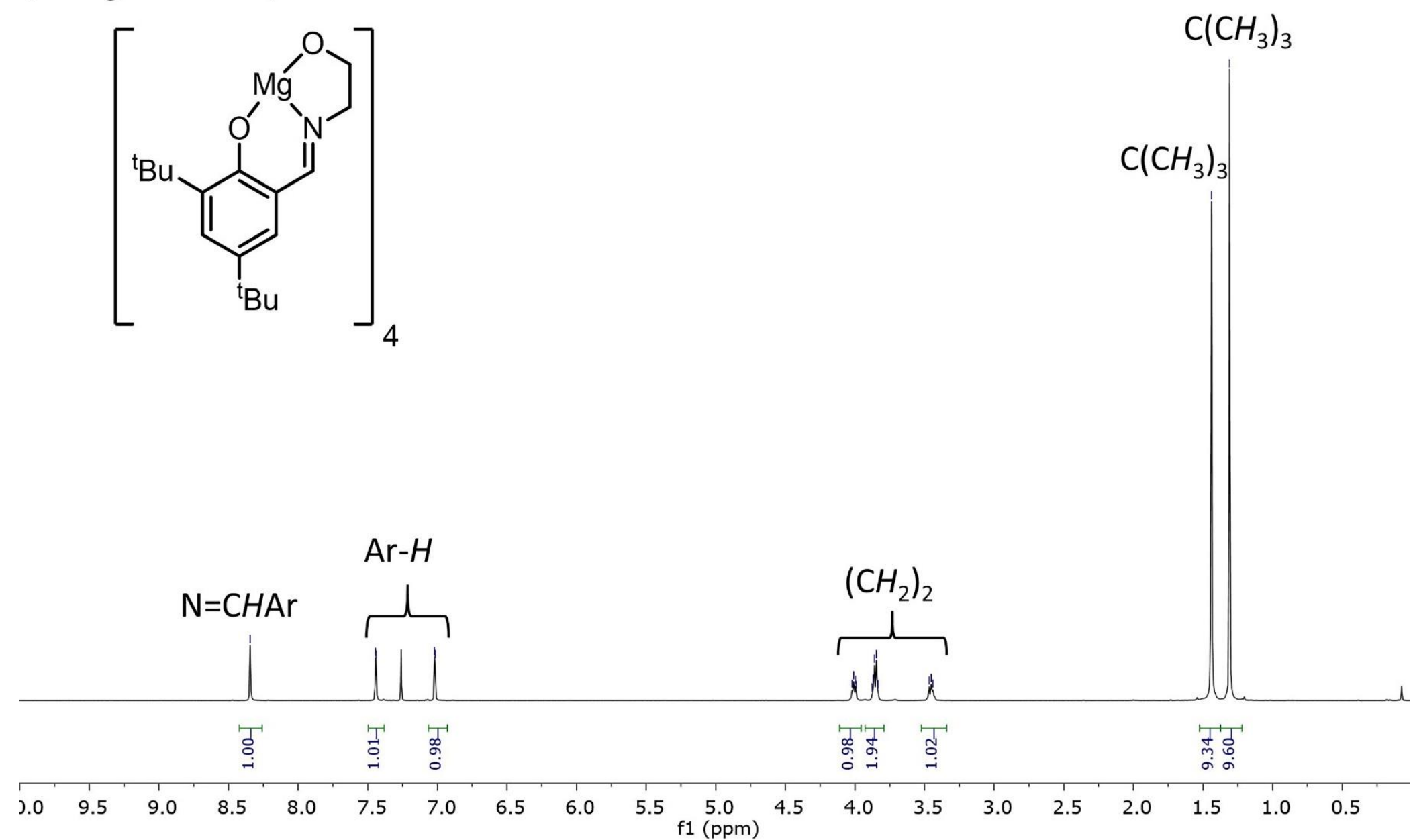

Figure $55{ }^{1} \mathrm{H}$ NMR spectrum $\left(\mathrm{CDCl}_{3}, 600 \mathrm{MHz}, 30{ }^{\circ} \mathrm{C}\right)$ of complex $3 \mathbf{a}$. 


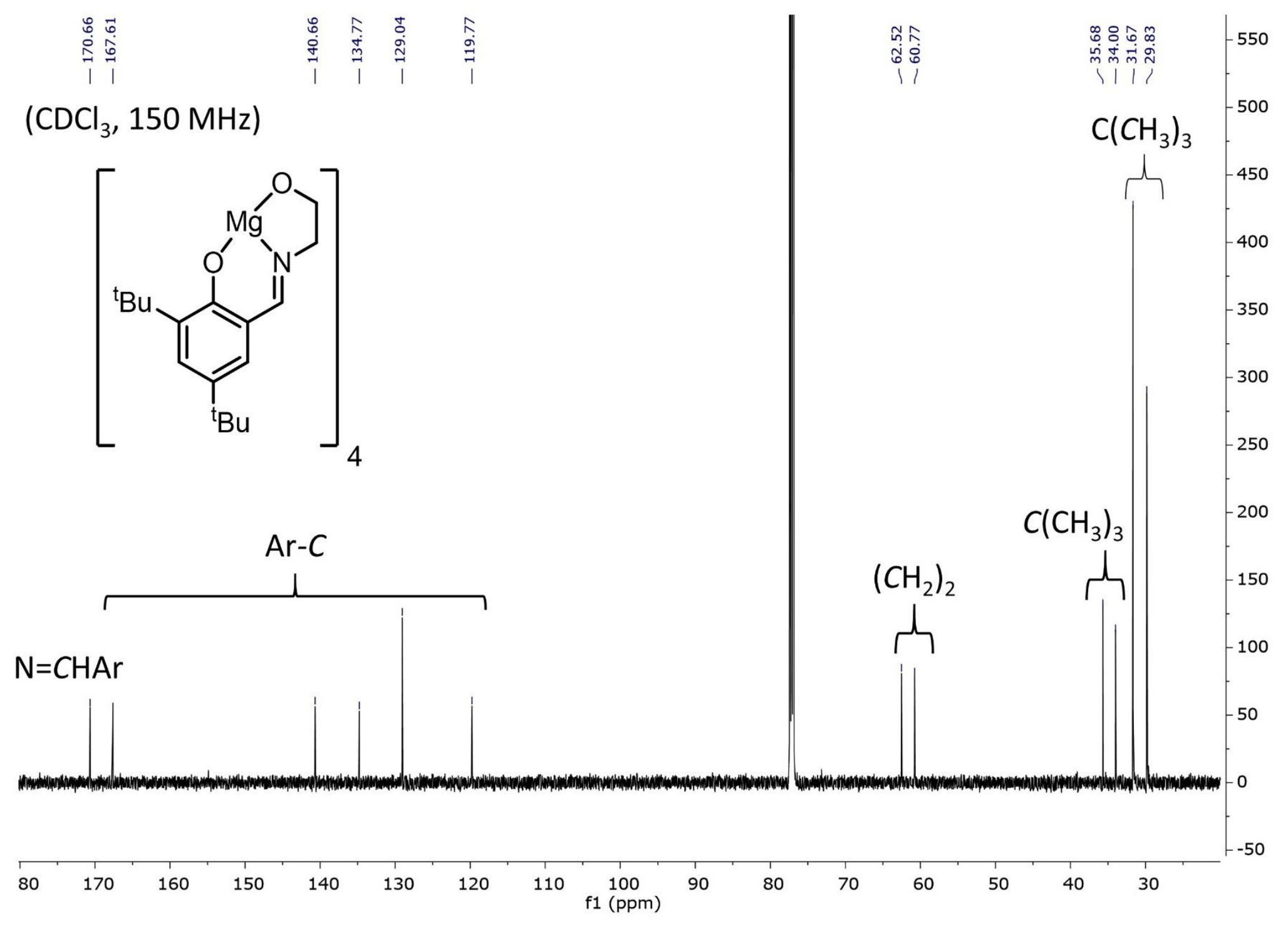

Figure $\mathbf{S 6}{ }^{13} \mathrm{C}$ NMR spectrum $\left(\mathrm{CDCl}_{3}, 150 \mathrm{MHz}, 30{ }^{\circ} \mathrm{C}\right)$ of complex 3 a. 


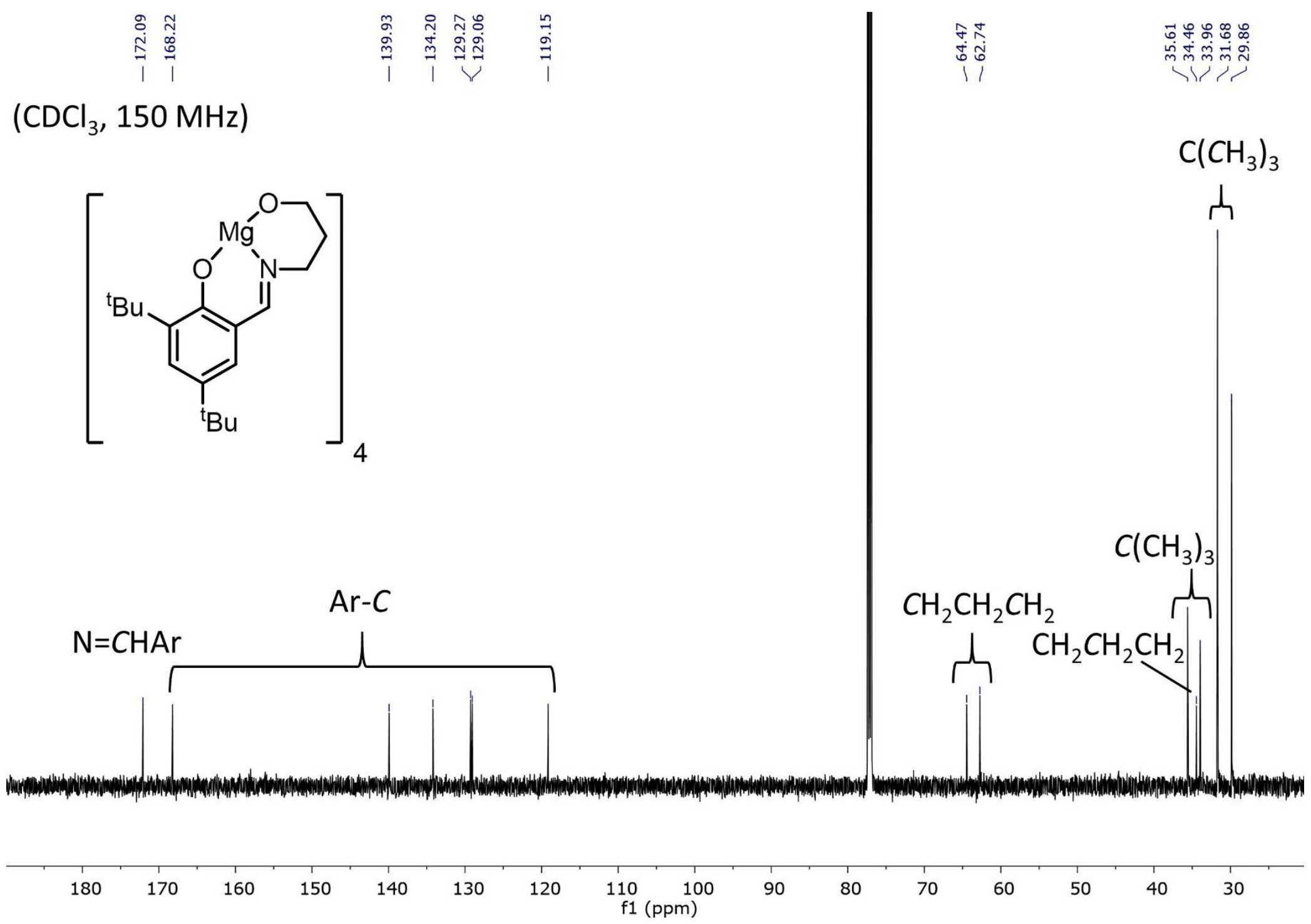

Figure $\mathbf{S 8}{ }^{13} \mathrm{C} \mathrm{NMR}$ spectrum $\left(\mathrm{CDCl}_{3}, 150 \mathrm{MHz}, 30{ }^{\circ} \mathrm{C}\right)$ of complex $\mathbf{3 b}$. 


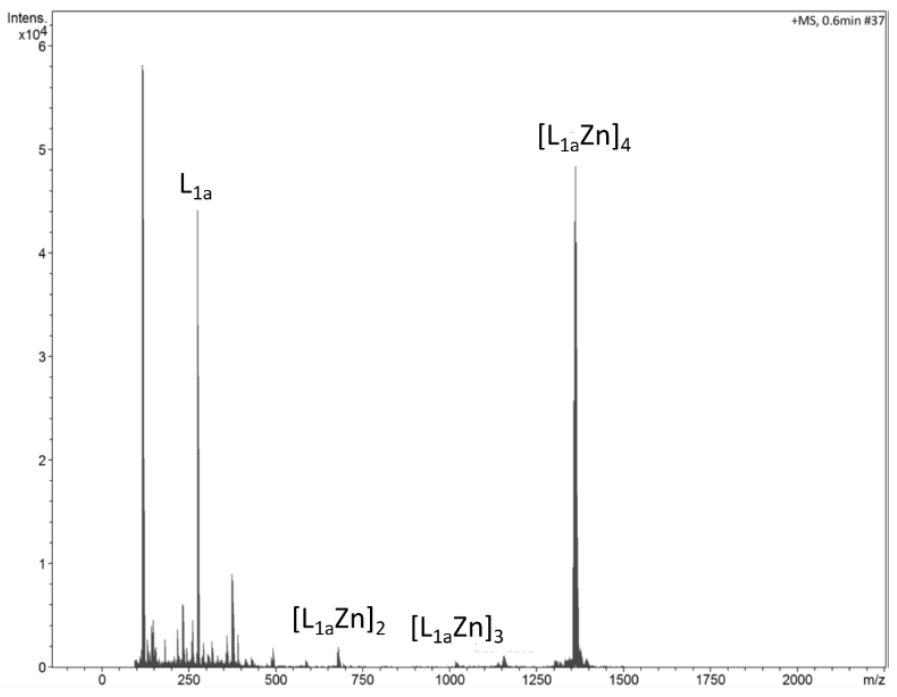<smiles></smiles>

\begin{tabular}{ccc}
\hline Species & Calculated & Observed \\
\hline$\left[\mathrm{L}_{1 \mathrm{a}} \mathrm{Zn}\right]_{4}$ & 1362.4650 & 1362.4635 \\
{$\left[\mathrm{~L}_{1 \mathrm{a}} \mathrm{Zn}\right]_{3}$} & 1021.3549 & 1021.3486 \\
{$\left[\mathrm{~L}_{1 \mathrm{a}} \mathrm{Zn}\right]_{2}$} & 680.2331 & 680.2323 \\
\hline
\end{tabular}

Figure S9 APCI mass spectrum of complex 2a.

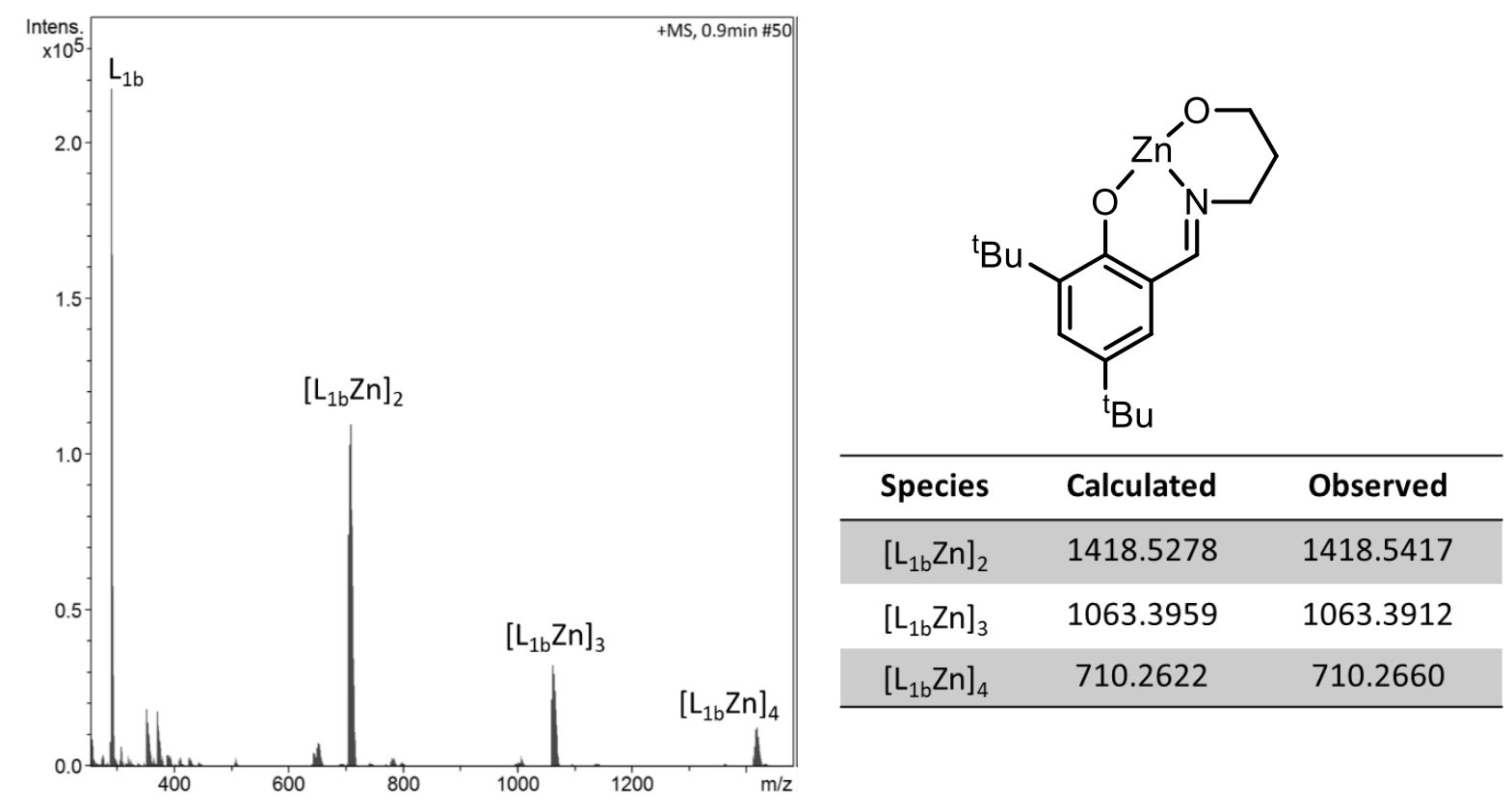

Figure S10 APCI mass spectrum of complex $\mathbf{2 b .}$ 


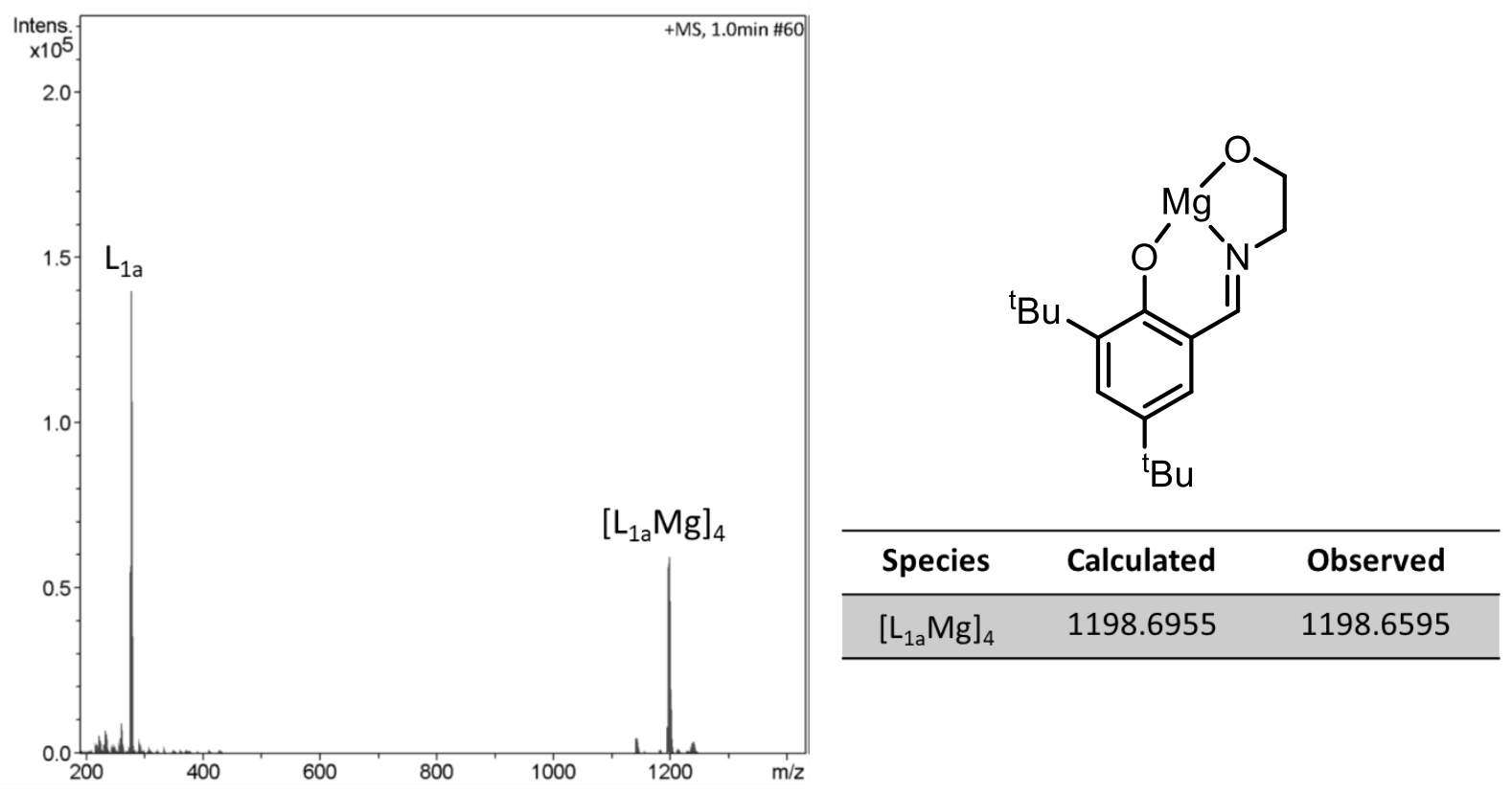

Figure S11 APCI mass spectrum of complex 3a.
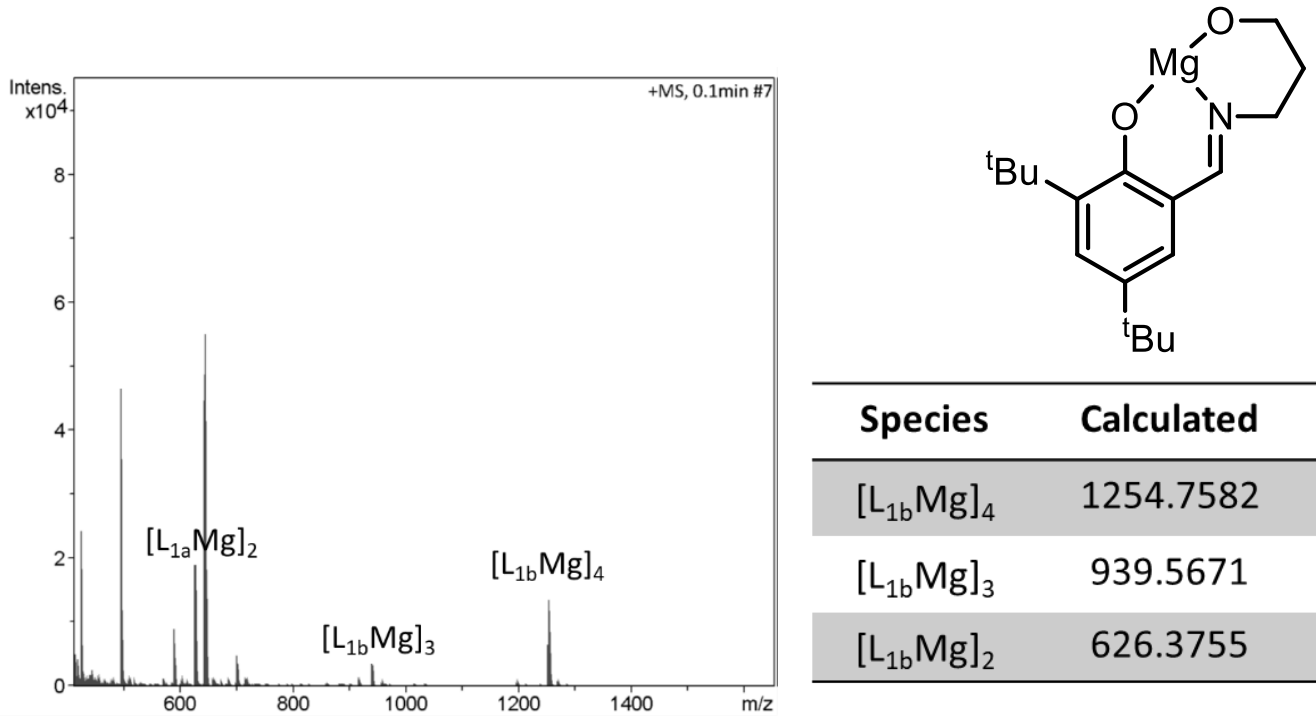

\begin{tabular}{ccc}
\hline Species & Calculated & Observed \\
\hline$\left[\mathrm{L}_{1 \mathrm{~b}} \mathrm{Mg}\right]_{4}$ & 1254.7582 & 1254.7788 \\
{$\left[\mathrm{~L}_{1 \mathrm{~b}} \mathrm{Mg}\right]_{3}$} & 939.5671 & 939.5683 \\
{$\left[\mathrm{~L}_{1 \mathrm{~b}} \mathrm{Mg}\right]_{2}$} & 626.3755 & 626.3779 \\
\hline
\end{tabular}

Figure S12 APCI mass spectrum of complex $\mathbf{3 b}$. 


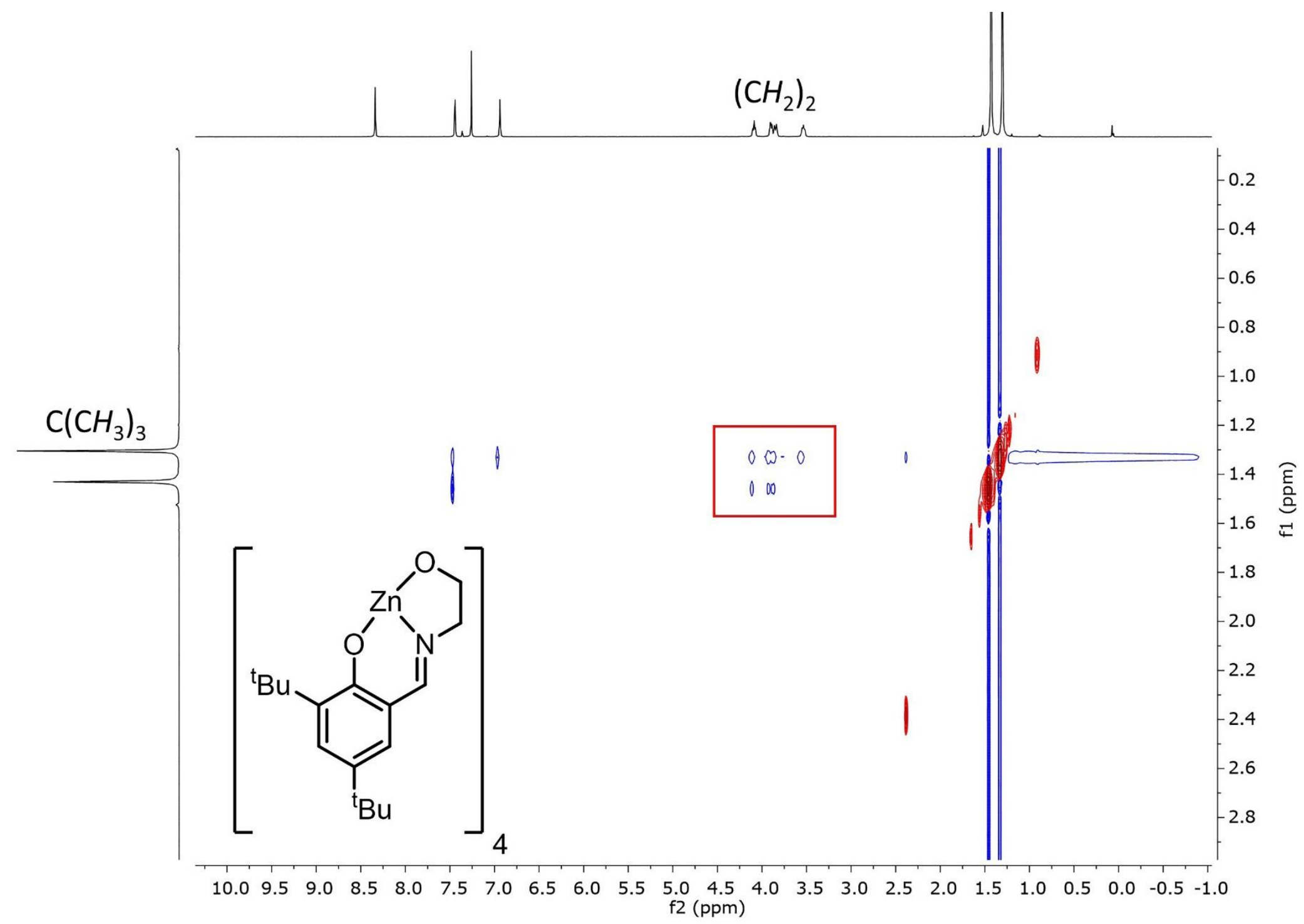

Figure S13 NOESY NMR spectrum $\left(\mathrm{CDCl}_{3}, 600 \mathrm{MHz}, 30^{\circ} \mathrm{C}\right)$ of complex $2 \mathbf{a}$. 


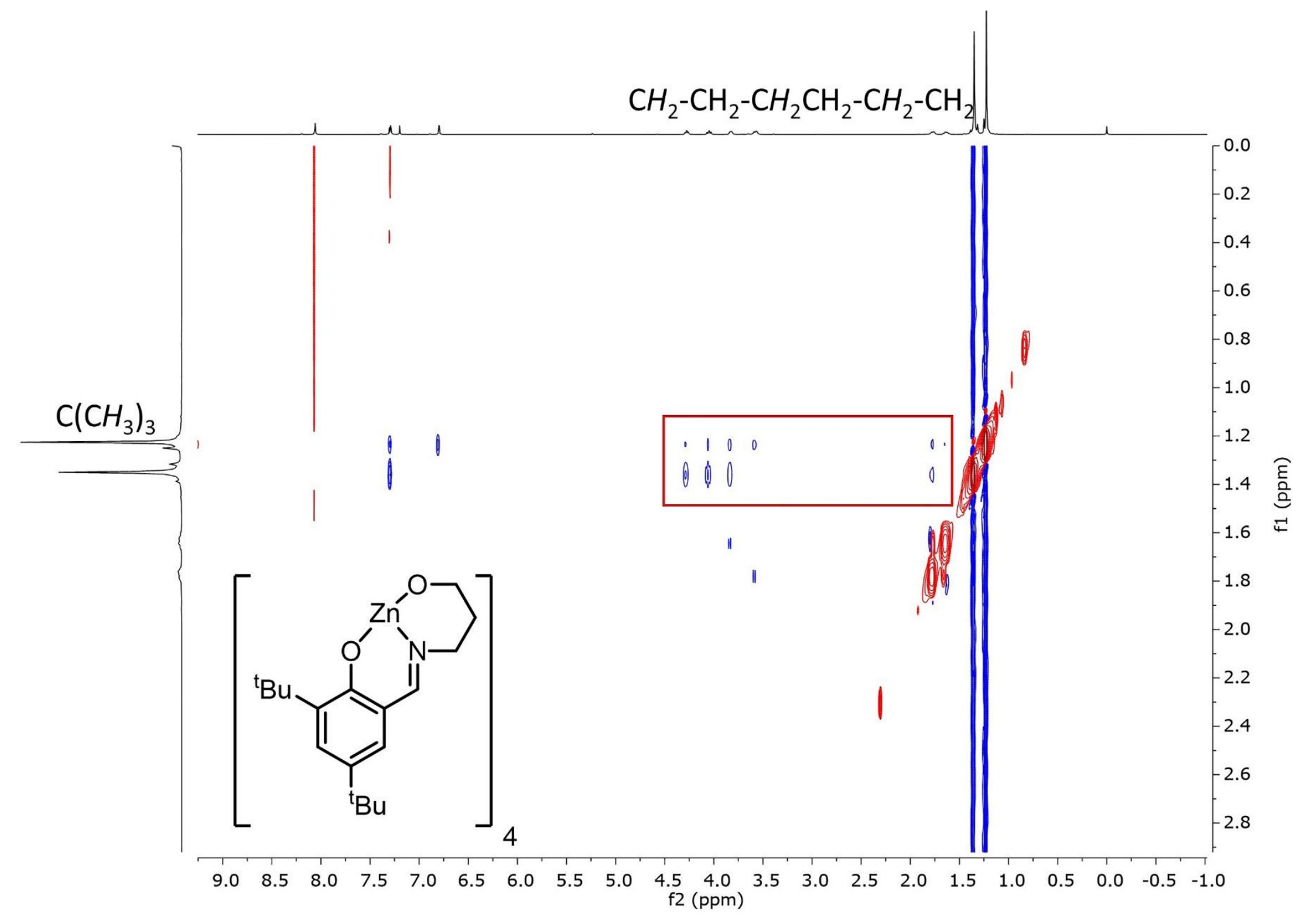

Figure S14 NOESY NMR spectrum $\left(\mathrm{CDCl}_{3}, 600 \mathrm{MHz}, 30^{\circ} \mathrm{C}\right)$ of complex $\mathbf{2 b}$. 


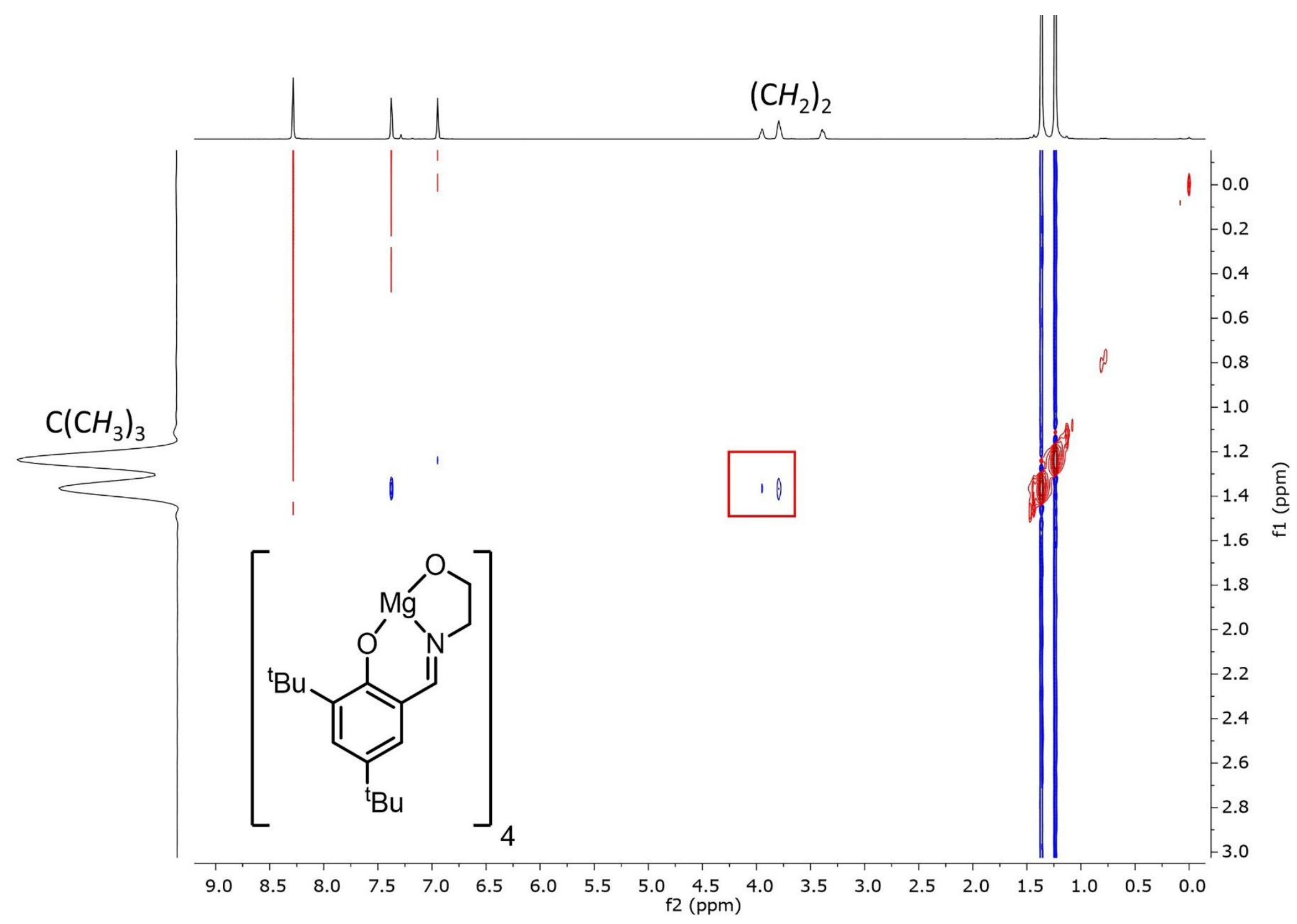

Figure S15 NOESY NMR spectrum $\left(\mathrm{CDCl}_{3}, 600 \mathrm{MHz}, 30^{\circ} \mathrm{C}\right)$ of complex 3a. 


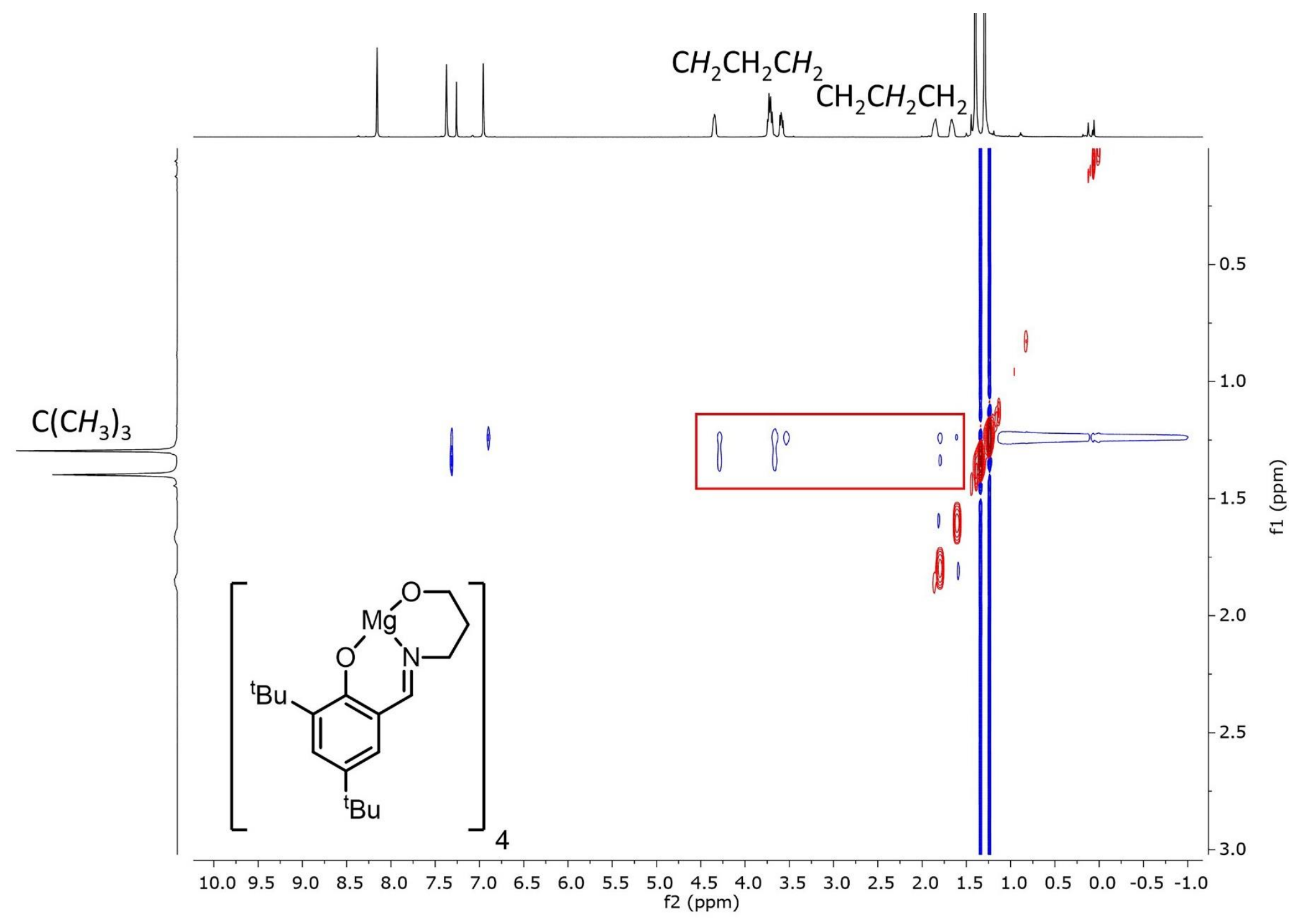

Figure S16 NOESY NMR spectrum $\left(\mathrm{CDCl}_{3}, 600 \mathrm{MHz}, 30^{\circ} \mathrm{C}\right)$ of complex $3 \mathrm{~b}$ 


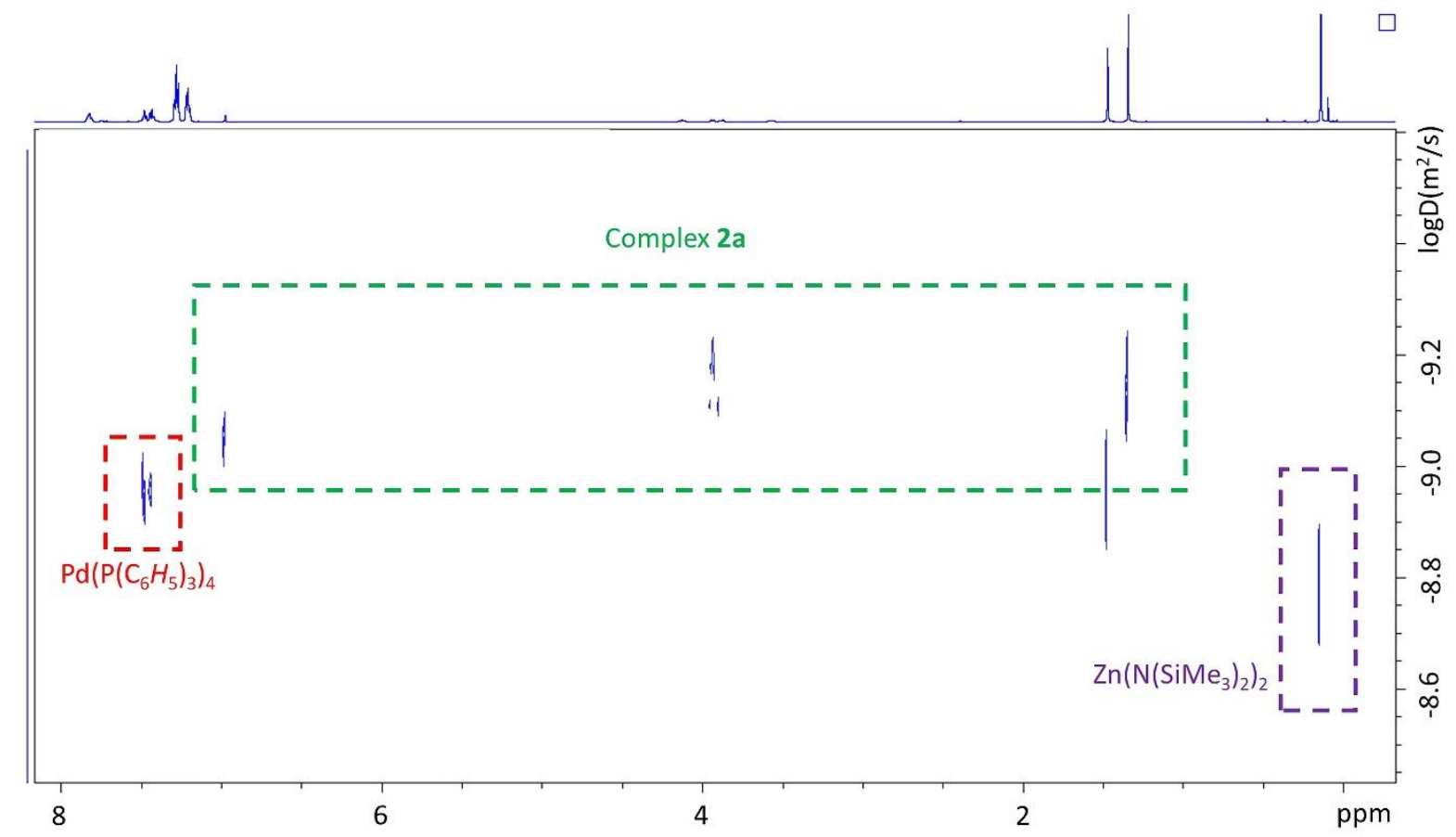

Figure S17 Diffusion-ordered spectroscopy (DOSY) NMR spectrum of complex 2a in $\mathrm{CDCl}_{3}$, 600 at $30{ }^{\circ} \mathrm{C}$ using tetrakis(triphenylphosphine) palldium $(0)\left(\mathrm{Pd}\left(\mathrm{P}\left(\mathrm{C}_{6} \mathrm{H}_{5}\right)_{3}\right)_{4}\right)$ and zinc bis(bis(trimethylsilylamide $)\left(\mathrm{Zn}\left(\mathrm{N}\left(\mathrm{SiMe}_{3}\right)_{2}\right)_{2}\right)$ as internal standards.

Table S1 Diffusion coefficient (D) and estimated molecular weight of complex 2a using $\left(\mathrm{Pd}\left(\mathrm{P}\left(\mathrm{C}_{6} \mathrm{H}_{5}\right)_{3}\right)_{4}\right)$ and zinc bis(bis(trimethylsilylamide $)\left(\mathrm{Zn}\left(\mathrm{N}\left(\mathrm{SiMe}_{3}\right)_{2}\right)_{2}\right)$ as internal standards.

\begin{tabular}{|c|c|c|}
\hline Compound & $\mathbf{D}\left(\mathbf{m}^{2} / \mathbf{s}\right)$ & Molecular weight (Da) \\
\hline $\mathrm{Zn}\left(\mathrm{N}\left(\mathrm{SiMe}_{3}\right)_{2}\right)_{2}$ & $1.77 \times 10^{-9}$ & 386.16 \\
\hline $\left.\mathrm{Pd}\left(\mathrm{P}_{6} \mathrm{C}_{6} \mathrm{H}_{5}\right)_{3}\right)_{4}$ & $1.04 \times 10^{-9}$ & 1155.59 \\
\hline Complex 2a & $9.12 \times 10^{-10}$ & 1536.99 (estimated) \\
\hline
\end{tabular}




\section{X-ray crystallographic data}

Table S2 Crystal and structure refinement data for complexes $\mathbf{2 a}, \mathbf{2 b}$, and $\mathbf{3 a}$

\begin{tabular}{|c|c|c|c|}
\hline Compound & $2 \mathbf{a}$ & $2 \mathbf{b}$ & $\mathbf{3 a}$ \\
\hline Elemental formula & $\mathrm{C}_{68} \mathrm{H}_{100} \mathrm{~N}_{4} \mathrm{O}_{9} \mathrm{Zn}_{4}$ & $\mathrm{C}_{22} \mathrm{H}_{35} \mathrm{NO}_{3} \mathrm{Zn}$ & $\mathrm{C}_{76} \mathrm{H}_{116} \mathrm{~N}_{4} \mathrm{O}_{10} \mathrm{Mg}$ \\
\hline Formula weight & 1362.99 & 524.70 & 1342.96 \\
\hline Crystal system & Tetragonal & Tetragonal & Tetragonal \\
\hline Space group & $P-42{ }_{1} c$ & $I 4_{l} / a$ & $I 4_{I} / a$ \\
\hline$a / \AA$ & $18.0663(7)$ & $27.854(12)$ & $22.701(12)$ \\
\hline$b / \AA$ & $18.0663(7)$ & $27.854(12)$ & $22.701(12)$ \\
\hline$c / \AA$ & $11.4492(4)$ & $11.242(5)$ & $15.038(8)$ \\
\hline$\alpha / 0$ & 90 & 90 & 90 \\
\hline$\beta / \circ$ & 90 & 90 & 90 \\
\hline$\gamma / 0$ & 90 & 90 & 90 \\
\hline Cell volume, $V / \AA^{3}$ & $3736.9(3)$ & $8722(8)$ & $7750(9)$ \\
\hline No. of formula units/cell, $Z$ & 2 & 16 & 4 \\
\hline$\rho_{\text {calc. }} / \mathrm{Mg} \mathrm{m}^{-3}$ & 1.204 & 1.300 & 1.300 \\
\hline$F(000)$ & 1424 & 3648 & 2912 \\
\hline Absorption coefficient, $\mu / \mathrm{mm}^{-1}$ & 1.32 & 1.15 & 1.10 \\
\hline$T / \mathrm{K}$ & 100 & 293 & $100(2)$ \\
\hline Crystal colour, shape & Colourless, Block & Yellow, Block & Colourless, Hexagonal \\
\hline Crystal size / mm & $0.20 \times 0.18 \times 0.18$ & $0.30 \times 0.13 \times 0.13$ & $0.21 \times 0.09 \times 0.06$ \\
\hline $\begin{array}{l}\text { Total no. of reflections measured } \\
\text { (not including absences) }\end{array}$ & 22819 & 32368 & 26672 \\
\hline $\begin{array}{l}\text { No. of unique reflections, and } R_{\text {int }} \text { for } \\
\text { equivalents }\end{array}$ & $4640,0.057$ & $4284,0.063$ & $3534,0.038$ \\
\hline No. of 'observed' reflections $\left(I>2 \sigma_{\mathrm{I}}\right)$ & 4112 & 3394 & 2938 \\
\hline Data/restraints/parameters & $4640 / 142 / 238$ & $4284 / 0 / 250$ & $3534 / 41 / 281$ \\
\hline Goodness-of-fit on $F^{2}, S$ & 1.059 & 1.091 & 1.043 \\
\hline$R$ indices ('observed' data) & $R_{1}=0.046, w R_{2}=0.098$ & $R_{1}=0.040, w R_{2}=0.094$ & $R_{1}=0.041, w R_{2}=0.108$ \\
\hline$R$ indices (all data) & $R_{1}=0.056, w R_{2}=0.143$ & $R_{1}=0.061, w R_{2}=0.110$ & $R_{1}=0.052, w R_{2}=0.117$ \\
\hline Largest diff. peak and hole / $\mathrm{e}^{-3}$ & 0.66 and -0.56 & 0.84 and -0.51 & 0.28 and -0.29 \\
\hline Flack parameter & $0.05(2)$ & & \\
\hline
\end{tabular}



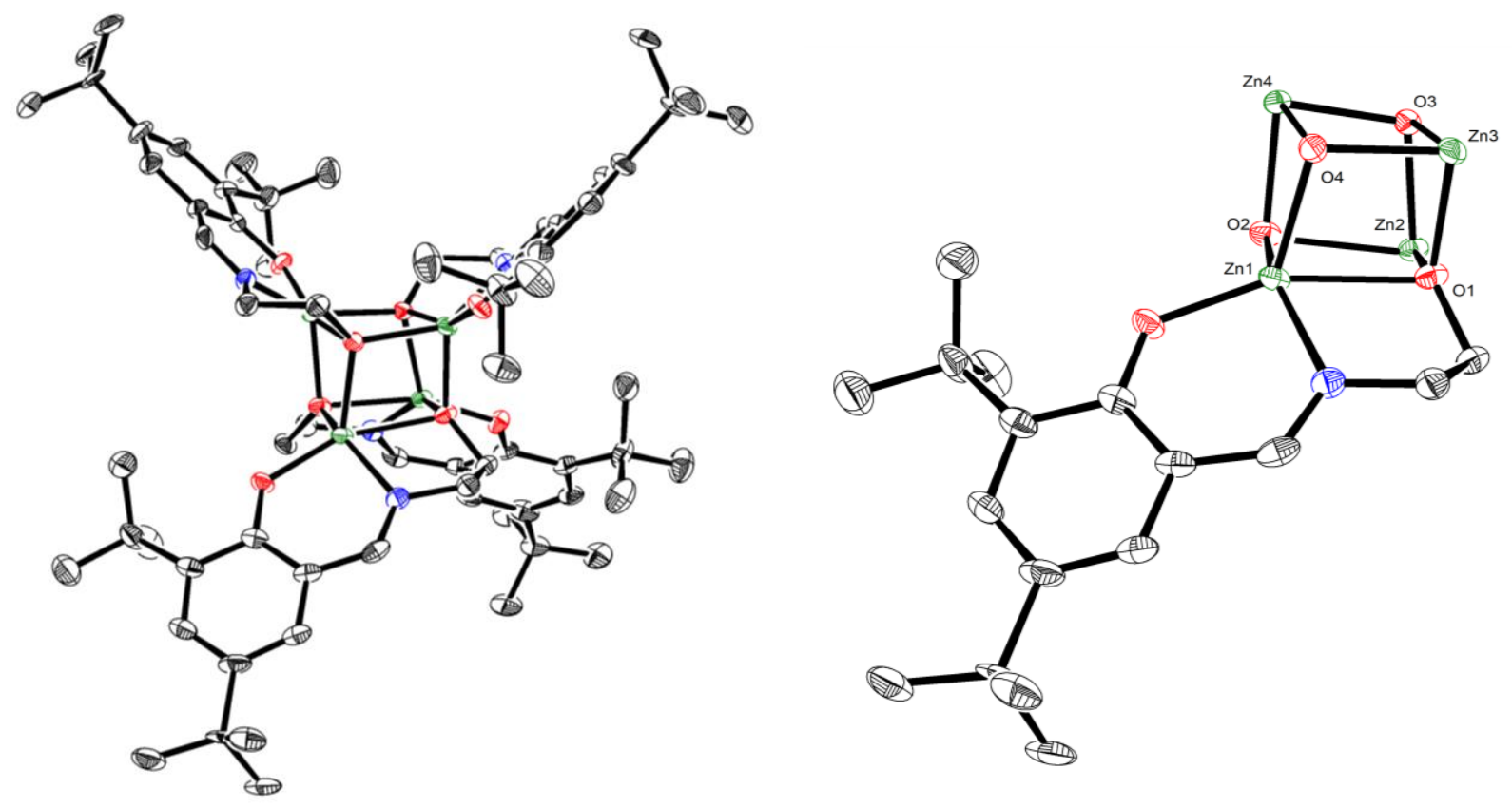

Figure S18 X-ray crystal structure of complex 2a with thermal ellipsoids drawn at 50\% probability level. Hydrogen atoms are omitted for clarity.

Table S3 Selected bond distances $(\AA)$ and angle $\left({ }^{\circ}\right)$ for complex 2a

\section{Complex 2a}

$\begin{array}{llllll}\mathrm{Zn} 1-\mathrm{O} 1 & 2.358(3) & \mathrm{Zn} 1-\mathrm{O} 1_{\mathrm{L}} & 1.948(3) & \mathrm{Zn1-O} 2 & 2.000(3) \\ \mathrm{Zn} 1-\mathrm{O} 4 & 1.998(3) & \mathrm{Zn} 1-\mathrm{N} 1 & 2.006(4) & \mathrm{O} 1-\mathrm{Zn} 1-\mathrm{O} 1_{\mathrm{L}} & 160.0(1) \\ \mathrm{O} 2-\mathrm{Zn} 1-\mathrm{N} 1 & 143.5(2) & \mathrm{O} 4-\mathrm{Zn} 1-\mathrm{N} 1 & 116.3(2) & \mathrm{O} 1-\mathrm{Zn} 1-\mathrm{N} 1 & 76.6(1) \\ \mathrm{O} 1_{\mathrm{L}}-\mathrm{Zn} 1-\mathrm{N} 1 & 92.8(2) & \mathrm{O} 1_{\mathrm{L}}-\mathrm{Zn} 1-\mathrm{O} 2 & 122.9(1) & \mathrm{O} 1_{\mathrm{L}}-\mathrm{Zn} 1-\mathrm{O} 4 & 98.5(1) \\ \mathrm{O} 2-\mathrm{Zn} 1-\mathrm{O} 1 & 77.1(1) & \mathrm{O} 4-\mathrm{Zn} 1-\mathrm{O} 1 & 81.4(1) & \mathrm{O} 2-\mathrm{Zn} 1-\mathrm{O} 4 & 86.1(1)\end{array}$



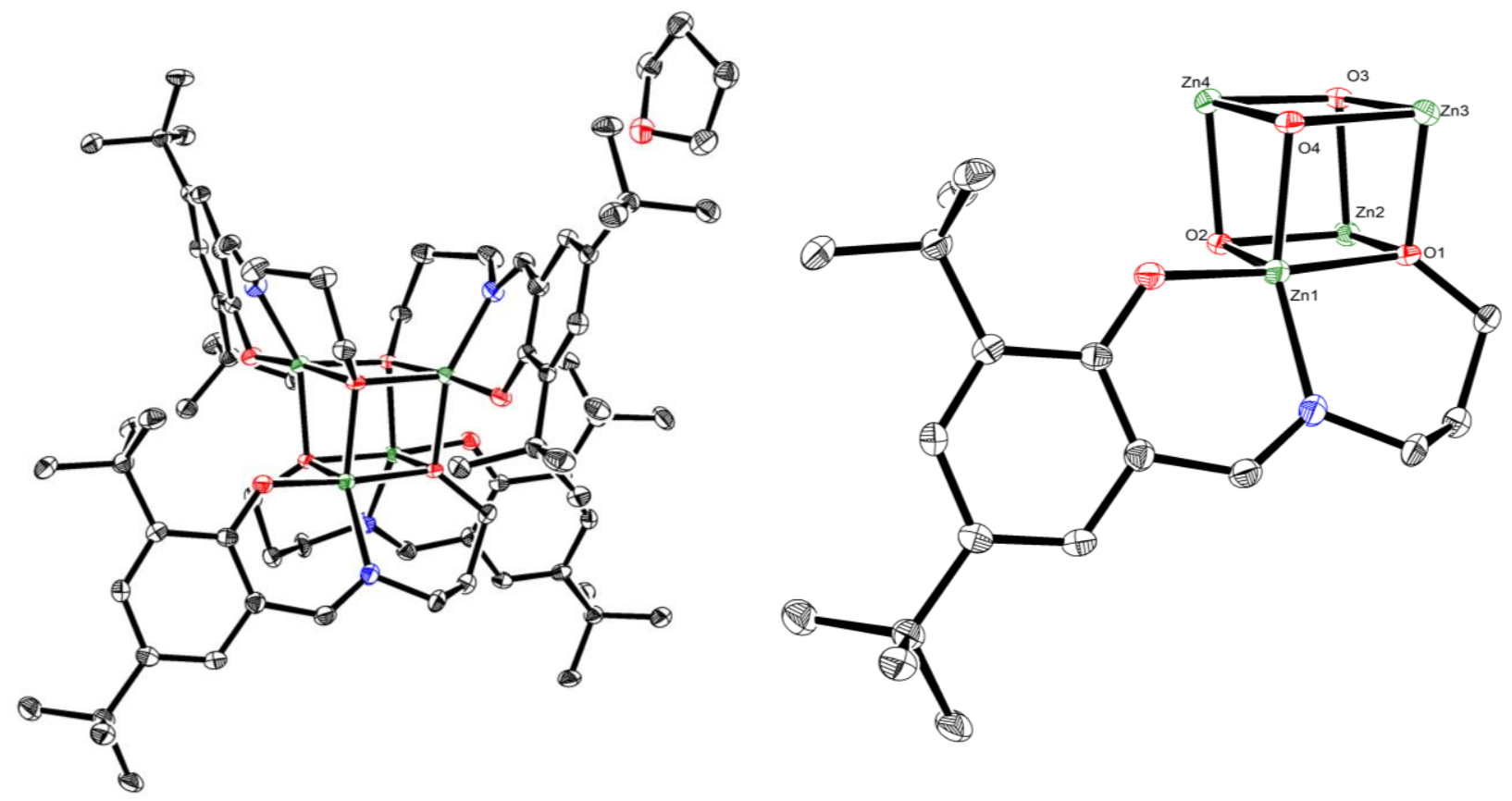

Figure S19 X-ray crystal structure of complex 2b with thermal ellipsoids drawn at 50\% probability level. Hydrogen atoms are omitted for clarity.

Table S4 Selected bond distances $(\AA)$ and angle $\left(^{\circ}\right)$ for complex $\mathbf{2 b}$

\begin{tabular}{llllll}
\hline \multicolumn{2}{c}{ Complex 2b } & & & & \\
$\mathrm{Zn} 1-\mathrm{O} 1$ & $2.176(2)$ & $\mathrm{Zn} 1-\mathrm{O} 1_{\mathrm{L}}$ & $1.977(2)$ & $\mathrm{Zn} 1-\mathrm{O} 2$ & $2.041(2)$ \\
$\mathrm{Zn} 1-\mathrm{O} 4$ & $2.044(2)$ & $\mathrm{Zn} 1-\mathrm{N} 1$ & $2.019(3)$ & $\mathrm{O} 1-\mathrm{Zn} 1-\mathrm{O} 1_{\mathrm{L}}$ & $175.3(1)$ \\
$\mathrm{O} 2-\mathrm{Zn} 1-\mathrm{N} 1$ & $123.1(1)$ & $\mathrm{O} 4-\mathrm{Zn} 1-\mathrm{N} 1$ & $149.8(1)$ & $\mathrm{O} 1-\mathrm{Zn} 1-\mathrm{N} 1$ & $92.7(1)$ \\
$\mathrm{O} 1_{\mathrm{L}}-\mathrm{Zn} 1-\mathrm{N} 1$ & $91.5(1)$ & $\mathrm{O} 1_{\mathrm{L}}-\mathrm{Zn} 1-\mathrm{O} 2$ & $98.5(1)$ & $\mathrm{O}_{\mathrm{L}}-\mathrm{Zn} 1-\mathrm{O} 4$ & $93.0(1)$ \\
$\mathrm{O} 2-\mathrm{Zn} 1-\mathrm{O} 1$ & $81.1(1)$ & $\mathrm{O} 4-\mathrm{Zn} 1-\mathrm{O} 1$ & $82.3(1)$ & $\mathrm{O} 2-\mathrm{Zn} 1-\mathrm{O} 4$ & $85.7(1)$
\end{tabular}



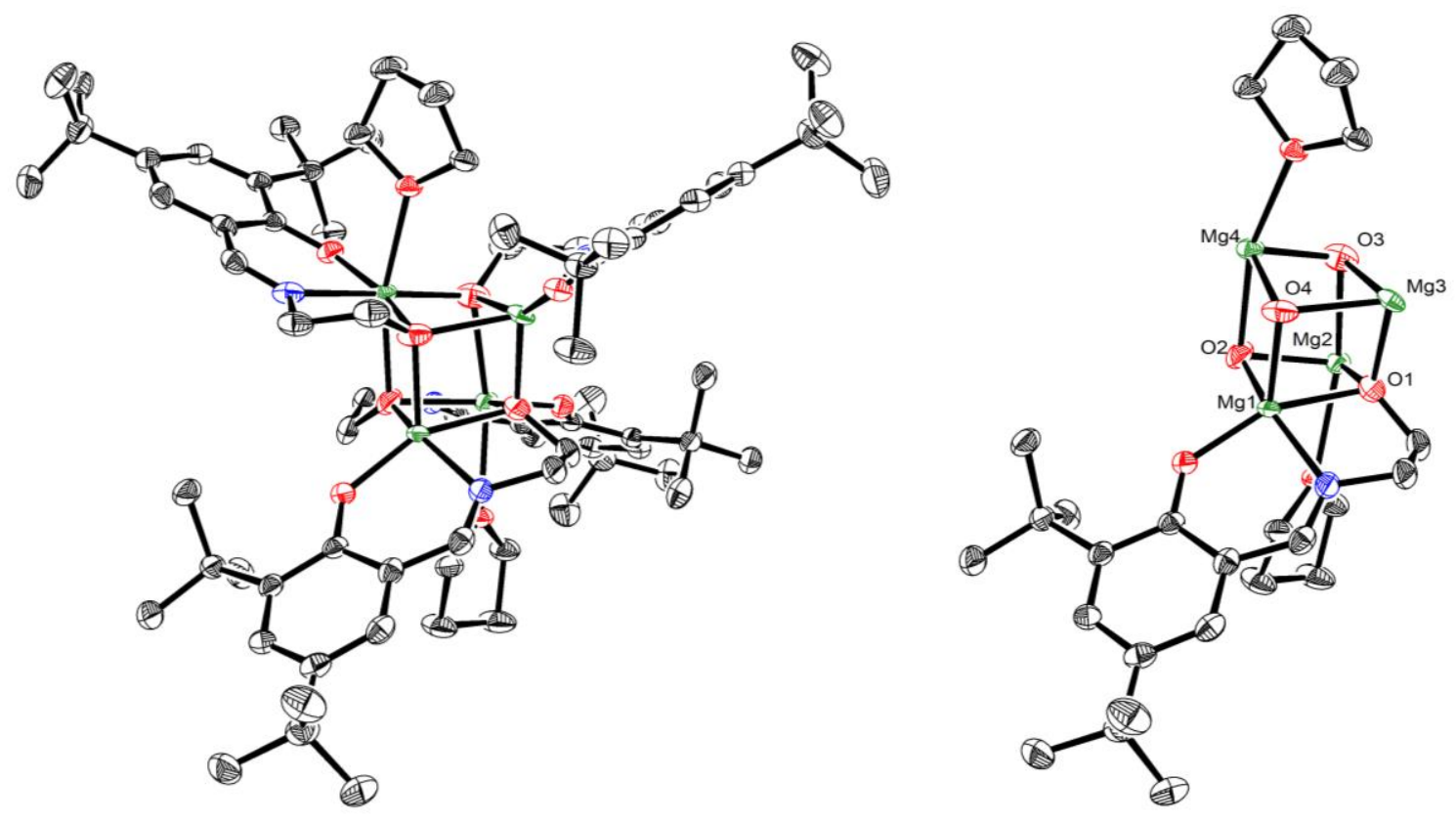

Figure S20 X-ray crystal structure of complex $\mathbf{2 b}$ with thermal ellipsoids drawn at 50\% probability level. Hydrogen atoms are omitted for clarity.

Table S5 Selected bond distances $(\AA)$ and angle $\left(^{\circ}\right)$ for complex $2 \mathbf{c}$

\begin{tabular}{llllll}
\hline \multicolumn{2}{c}{ Complex 3a } & & & & \\
$\mathrm{Mg} 1-\mathrm{O} 1$ & $2.172(5)$ & $\mathrm{Mg} 1-\mathrm{O} 1 \mathrm{~L}$ & $1.915(5)$ & $\mathrm{Mg} 1-\mathrm{O} 2$ & $2.173(4)$ \\
$\mathrm{Mg} 1-\mathrm{O} 4$ & $1.954(4)$ & $\mathrm{Mg} 1-\mathrm{N} 1$ & $2.036(5)$ & $\mathrm{Mg} 2-\mathrm{O}_{\mathrm{THF}}$ & $2.366(4)$ \\
$\mathrm{Mg} 2-\mathrm{O} 1$ & $1.899(5)$ & $\mathrm{Mg} 2-\mathrm{O} 3$ & $2.237(4)$ & $\mathrm{O} 1-\mathrm{Mg} 1-\mathrm{O} 1_{\mathrm{L}}$ & $155.0(2)$ \\
$\mathrm{O} 2-\mathrm{Mg} 1-\mathrm{N} 1$ & $150.5(2)$ & $\mathrm{O} 4-\mathrm{Mg} 1-\mathrm{N} 1$ & $115.8(2)$ & $\mathrm{O} 1-\mathrm{Mg} 1-\mathrm{N} 1$ & $79.5(2)$ \\
$\mathrm{O} 1 \mathrm{~L}-\mathrm{Mg} 1-\mathrm{N} 1$ & $89.7(2)$ & $\mathrm{O} 1_{\mathrm{L}}-\mathrm{Mg} 1-\mathrm{O} 2$ & $99.7(2)$ & $\mathrm{O} 1_{\mathrm{L}}-\mathrm{Mg} 1-\mathrm{O} 4$ & $122.3(2)$ \\
$\mathrm{O} 2-\mathrm{Mg} 1-\mathrm{O} 1$ & $80.5(2)$ & $\mathrm{O} 4-\mathrm{Mg} 1-\mathrm{O} 1$ & $82.6(2)$ & $\mathrm{O} 2-\mathrm{Mg} 1-\mathrm{O} 4$ & $82.6(2)$
\end{tabular}




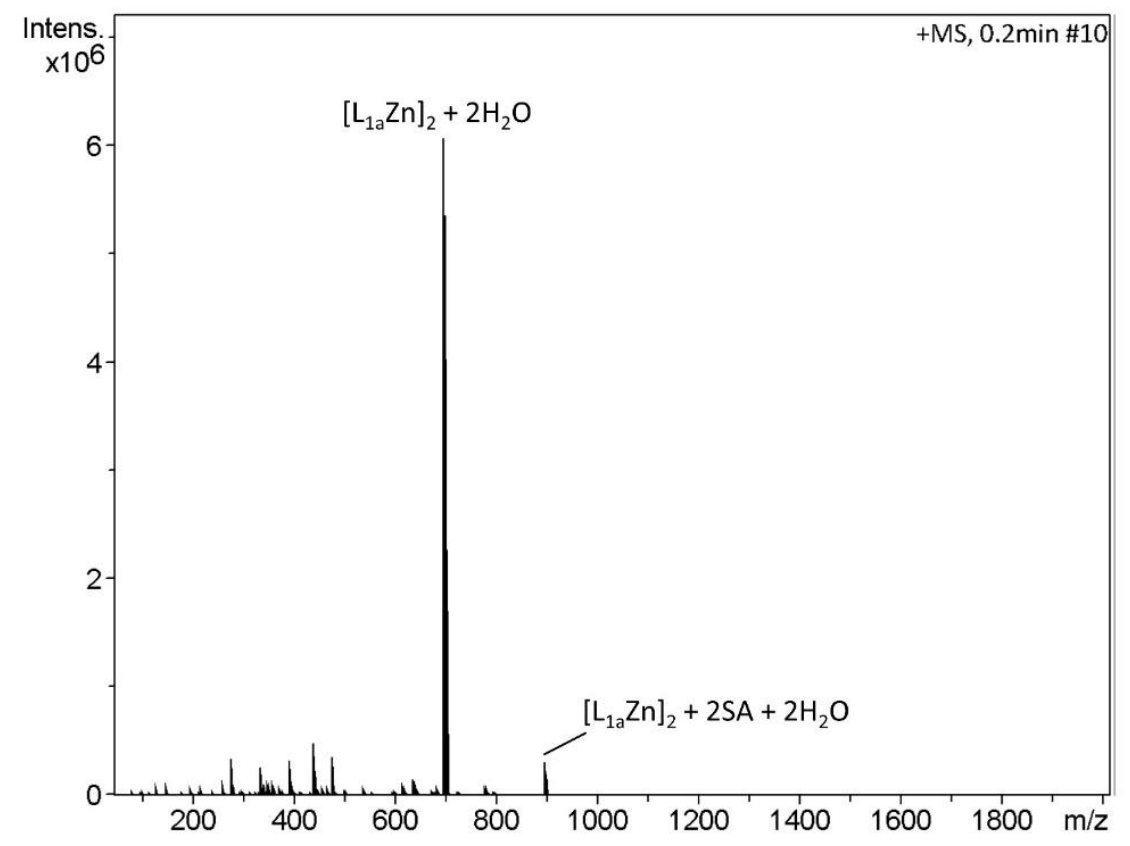

Figure S21 APCI mass spectrum of complex $2 \mathbf{a}+1.0$ equiv. of SA at $110{ }^{\circ} \mathrm{C}$.

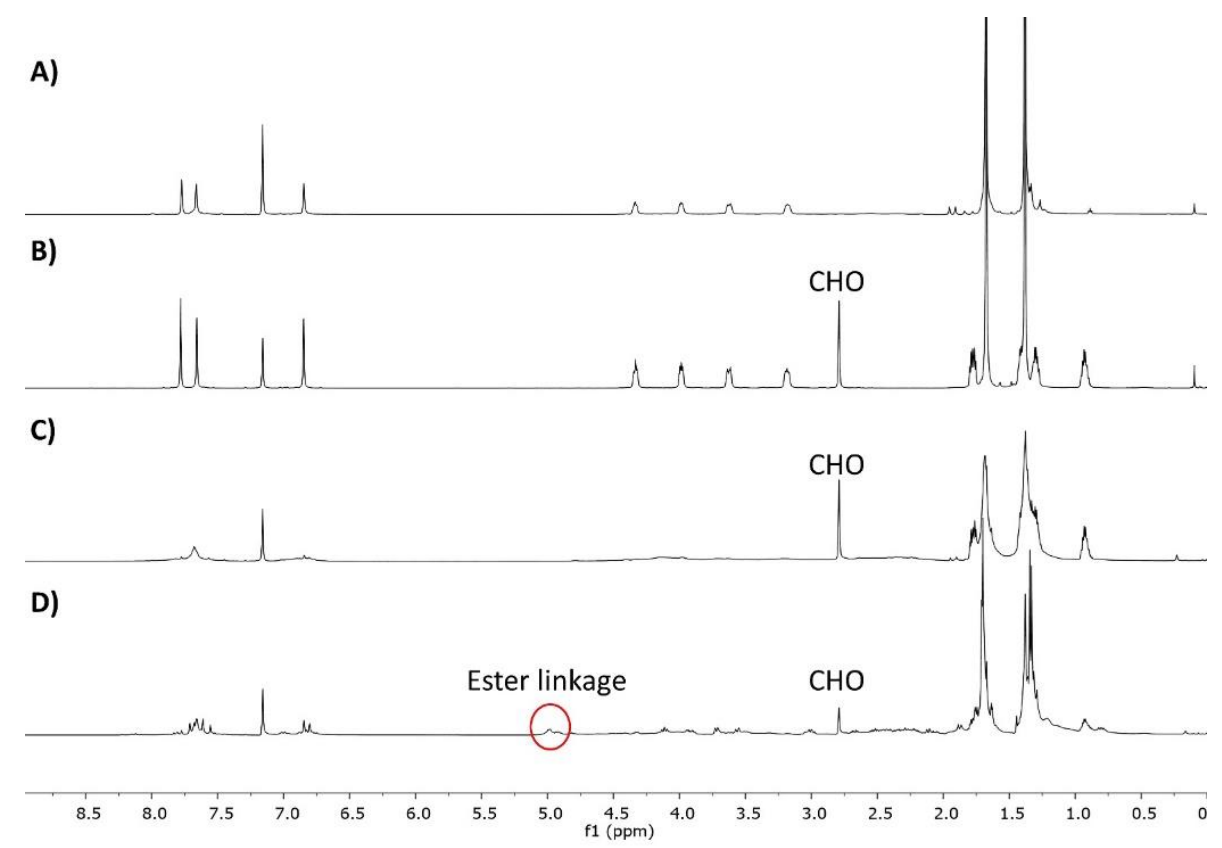

Figure S22 Series of ${ }^{1} \mathrm{H}$ NMR spectra $\left(\mathrm{C}_{6} \mathrm{D}_{6}, 600 \mathrm{MHz}, 30{ }^{\circ} \mathrm{C}\right)$ of (A) complex 2a (top), (B) then add 1.0 equiv. of $\mathrm{CHO}$ overnight at $110^{\circ} \mathrm{C},(\mathrm{C})$ then add 1.0 equiv. of $\mathrm{SA}$ for $15 \mathrm{~min}$, (D) then left overnight. 


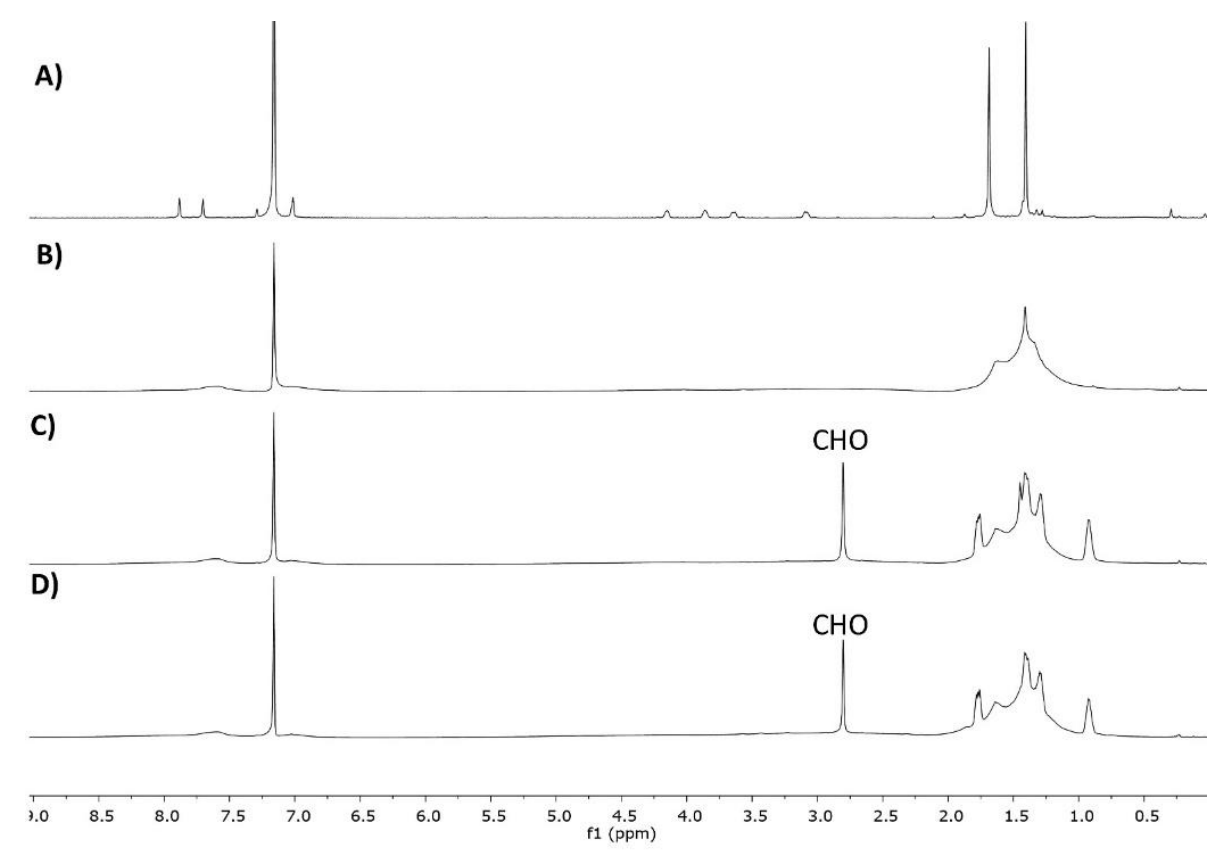

Figure S23 Series of ${ }^{1} \mathrm{H}$ NMR spectra $\left(\mathrm{C}_{6} \mathrm{D}_{6}, 600 \mathrm{MHz}, 30{ }^{\circ} \mathrm{C}\right)$ of (A) complex 3a (top), (B) then add 1.0 equiv. of $\mathrm{SA}$ for $15 \mathrm{~min}$ at $110^{\circ} \mathrm{C}$, (C) then add 1.0 equiv. of $\mathrm{CHO}$ for $15 \mathrm{~min}$, (D) then left overnight.

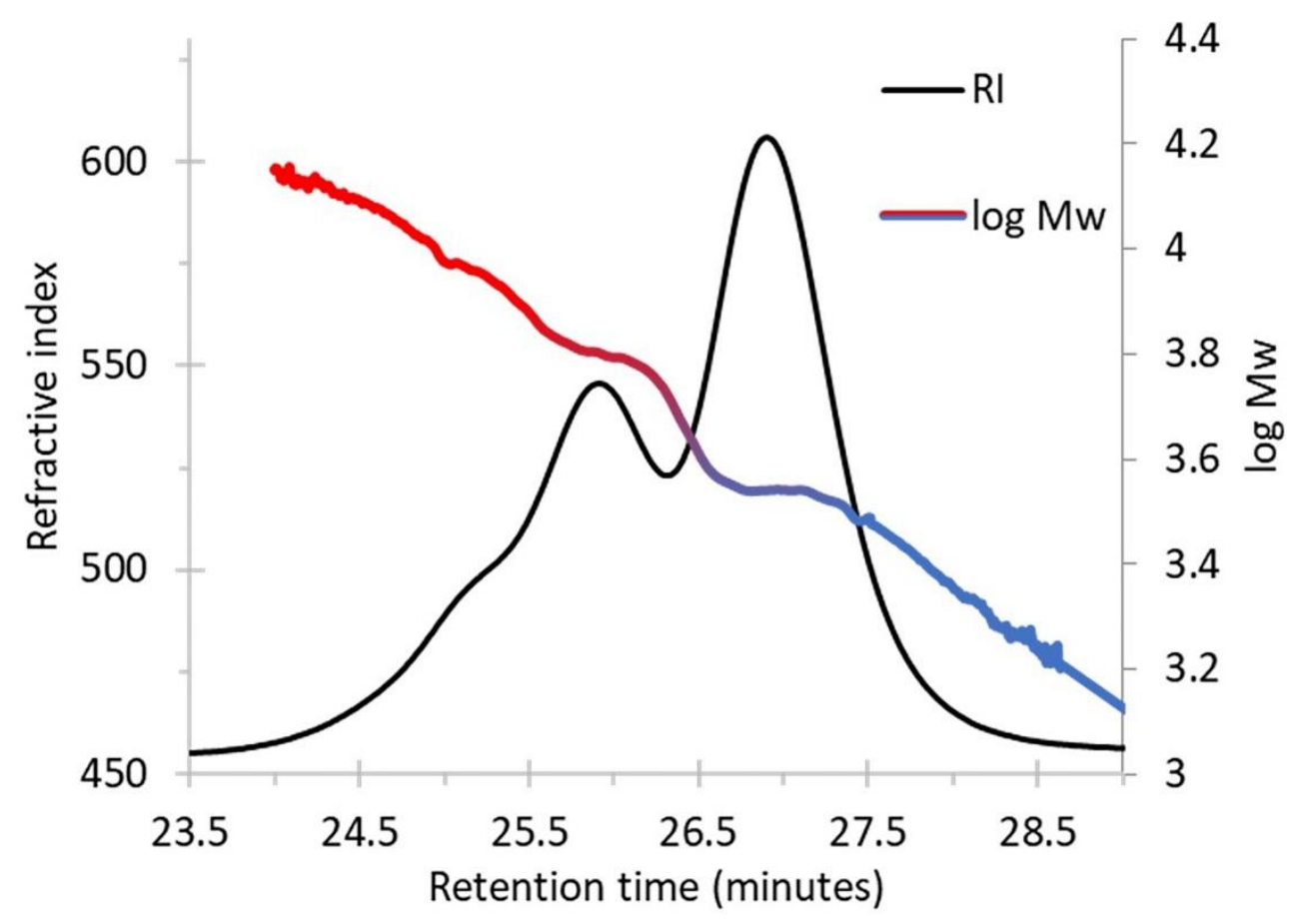

Figure S24 GPC profile and log molecular weight, of polymer produced by complex $\mathbf{2 a}$ using $\mathrm{CHO}: \mathrm{SA}: \mathbf{2 a}=27.5: 25: 1$ at $110{ }^{\circ} \mathrm{C},[\mathrm{CHO}]_{0}=0.5 \mathrm{M}$ for $4 \mathrm{~h}($ Table1, entry10). 


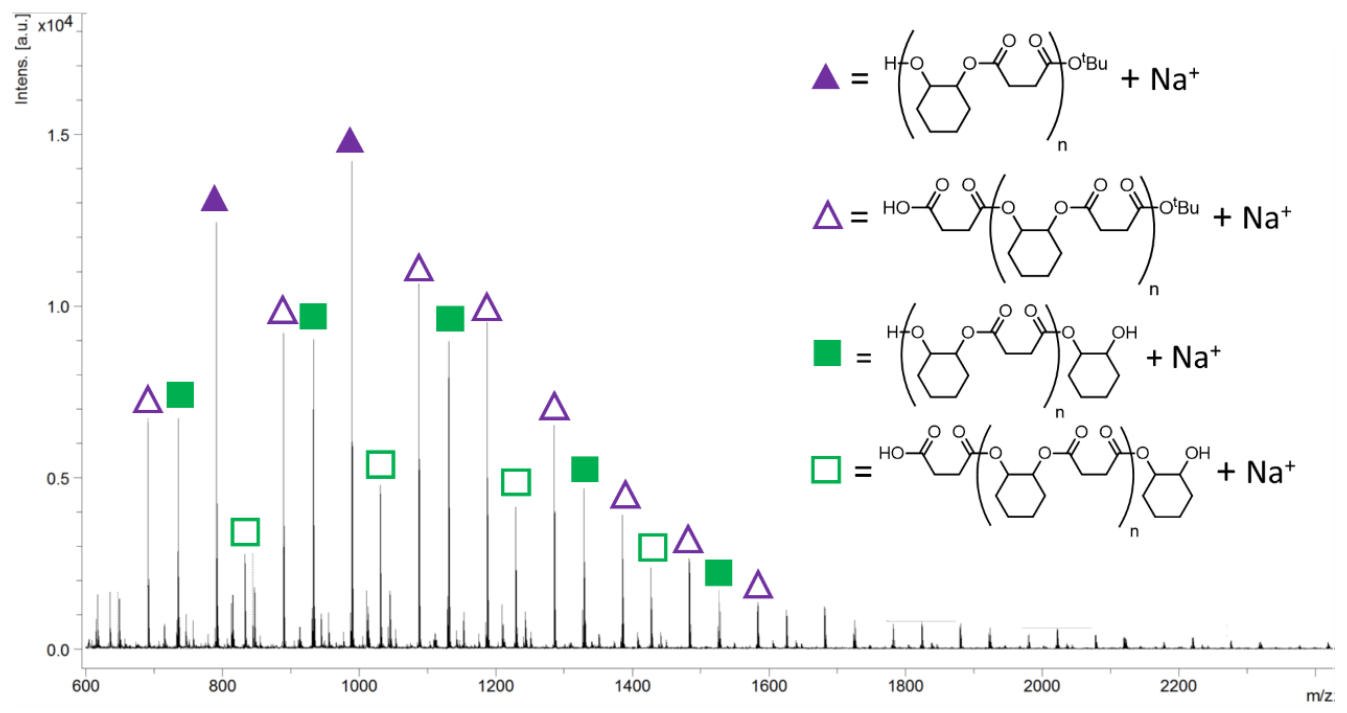

Figure S25 MALDI-TOF mass spectrum of linear model where $\Delta=\mathrm{H}-(\mathrm{CHO}-\mathrm{SA})_{n}-\mathrm{O}^{\mathrm{t}} \mathrm{Bu}+\mathrm{Na}^{+}, \triangle=$ $\mathrm{H}-\mathrm{SA}-(\mathrm{CHO}-\mathrm{SA})_{n}-\mathrm{O}^{t} \mathrm{Bu}+\mathrm{Na}^{+}, \quad=\mathrm{H}-(\mathrm{CHO}-\mathrm{SA})_{n}-\mathrm{CHD}+\mathrm{Na}^{+}$, and $\square=\mathrm{H}-\mathrm{SA}-(\mathrm{CHO}-\mathrm{SA})_{n}-\mathrm{CHD}+\mathrm{Na}^{+}$. 